\title{
Loss to Follow-Up Predisposition Factors in HIV and AIDS Patients with ARV Therapy
}

\author{
Tuti Susilowati ${ }^{1,2 *}$, Sutaryono ${ }^{3}$, Tri Nur Kristina ${ }^{4}$, Muchlis A U Sofro ${ }^{5}$
}

\author{
${ }^{1}$ Doctoral Program in Medical and Health Sciences, Universitas Diponegoro, Semarang, Indonesia \\ ${ }^{2}$ Permata Indonesia, Health Polytechnic Yogyakarta, Yogyakarta, Indonesia \\ ${ }^{3}$ Department of Pharmacy, Sekolah Tinggi Ilmu Kesehatan Muhammadiyah Klaten, Klaten, Indonesia \\ ${ }^{4}$ Faculty of Medicine, Universitas Diponegoro, Semarang, Indonesia \\ ${ }^{5}$ Dr. Kariadi Hospital, Semarang, Indonesia \\ *Corresponding author. Email: iyya_salaman@yahoo.co.id
}

\begin{abstract}
Human Immunodeficiency Virus (HIV) and Acquired Immune Deficiency Syndrome (AIDS) are diseases that require special treatment and therapy. Many factors affect the occurrence of failure of antiretroviral therapy (ARV). The purpose of this study was to determine the predisposing factors of loss to follow-up in HIV and AIDS patients with ARV therapy in Semarang. Observational research design, subjects were 70 respondents with the range of age about 18-65 years old with the inclusion of HIV patients who were loss to follow up in VCT services in Semarang in 2018. Predisposing variables consist of age, sex, education, occupation, marital status. The data on predisposing were collected by questionnaire, and loss to follow up was based on medical records. The data were analyzed using Odds Ratio and Chi square with a Confidence Interval (CI) of 95\%. Most respondents who experienced loss to follow up were male (64\%), aged 34 years, as a worker and many were unmarried. Predisposing variables that influence loss to follow up are age $18-35(\mathrm{OR}=2.88 ; 95 \% \mathrm{CI}=$ 1.061 to $7.84 ; \mathrm{p}=0.035)$ and occupation $(\mathrm{OR}=3 ; 95 \% \mathrm{CI}=1.020$ to $8.992 ; \mathrm{p}=0.042)$. Predisposing factors to age and occupation increase the risk of loss to follow up in HIV and AIDS patients on ARV therapy.
\end{abstract}

Keywords: predisposition, HIV/AIDS, ARV therapy

\section{INTRODUCTION}

The prevalence of Human Immunodeficiency Virus (HIV) and Acquired Immune Deficiency Syndrome (AIDS) in the world is increasing until the end of 2017. There were around 36.9 million people, 35.1 million people were adults and 940.000 people died. From this data, 21.7 million people received antiretroviral therapy, and 59\% of people living with HIV received antiretroviral therapy [1], [2].

In Indonesia, until the beginning of March 2018, there were 291.129 people with HIV/AIDS, and there were 106.965 people with AIDS with a percentage of deaths of $0.28 \%$. The highest number of HIV cases was in Jakarta (53.530), East Java (41.763), West Java (30.264), Papua (29.710), and Central Java (23.508). Based on cumulative numbers until January 17th, 2019, the highest AIDS data was reported from Papua (22.538), East Java (19.829), Jakarta (9.932), Central Java (10.111) and West Java (6.749) [3].

One of the causes of HIV/AIDS is the lack of awareness of people with HIV toward the importance of antiretroviral therapy (ARV), this is supported by the discovery of the Loss to follow-up (LTFU) case that is increasing. Based on the HIV and AIDS information system of the Indonesian Ministry of Health until September 2017, the Loss to Follow up (LTFU) data were 43.707 (22\%), while for Central Java from 2005 to August 2018, the Loss to Follow up data were 3.227 people (23\%).[3] Data of HIV morbidity, infections of opportunistic and mortality have increased, although there are some programs such as three zero and track phases that $90 \%$ have been applied, this shows that there are still gaps in the case of accessing ARV therapy [1], [3], [4].

Human Immunodeficiency Virus (HIV) and Acquired Immune Deficiency Syndrome (AIDS) are the diseases that require special treatment and therapy [1], [5], [6]. Antiretroviral therapy (ARV) requires people infected with HIV/AIDS to be more consistent in taking medication for life, so it requires high commitment from people living with HIV/AIDS (ODHA) in order to survive longer [7]-[9]. Maintaining ARV compliance can minimize LTFU and will reduce mortality [10]-[12]. Many factors influence the failure of Antiretroviral therapy (ARV), including the patient's characteristics as a predisposing factor. Therefore, this study aims to determine the relationship of predisposing factors of loss to follow up (LTFU) in patients with HIV and AIDS with ARV therapy in Semarang.

\section{METHOD}

The design used in this study is analytic observational with retrospective approach. The population in this study were all PWHA who have visited VCT clinic services and have been recorded in the medical record since 2017. The sampling technique used is non-random sampling which was quota sampling. The sample were 70 respondents with inclusion criteria of HIV patients who were Loss to Follow Up in VCT services in Semarang in 2018, with the ages of 
18-65 years. Predisposing variables consist of age, sex, education, occupation, and marital status. The data on predisposing were collected by employing questionnaire and Loss to Follow Up based on medical records. The data were analyzed using Odds Ratio and Chi-square with Confidence Interval (CI) of 95\%.

\section{RESULTS AND DISCUSSION}

The results of research in care, support and treatment in VCT service Semarang, showed that respondents' characteristics were mostly male $(64 \%)$, with the average age 34 years, higher education $(64.3 \%)$, workers $(58.6 \%)$, and unmarried $(53.9 \%)$. The results of the bivariate analysis of predisposing factors that influence the occurrence of Loss to Follow Up can be seen in Table 1.

Table 1 Predisposing factors of LTFU in HIV/AIDS patients on ARV therapy in Semarang

\begin{tabular}{|c|c|c|c|c|c|}
\hline \multirow{2}{*}{ No. } & \multirow{2}{*}{ Research Variables } & \multirow{2}{*}{ RP/OR } & \multicolumn{2}{|c|}{$95 \%$ CI } & \multirow{2}{*}{ P value } \\
\hline & & & lower & Upper & \\
\hline 1 & Ages $18-35$ & 2.88 & 1.061 & 7.840 & 0.035 \\
\hline 2 & Gender & 1.00 & 0.369 & 2.713 & 1.000 \\
\hline 3 & Education & 2.250 & 0.786 & 6.438 & 0.127 \\
\hline 4 & Employment Status & 3.029 & 1.020 & 8.992 & 0.042 \\
\hline 5 & Marital status & 0.826 & 0.317 & 2.153 & 0.698 \\
\hline
\end{tabular}

\subsection{Age and Incidence of LTFU}

Statistical results for ages $18-35$ were found $(\mathrm{OR}=2.88$; $95 \% \mathrm{CI}=1.061$ to $7.84 ; \mathrm{p}=0.035)$. Based on statistical analysis, there was an influence of ages characteristics on LTFU. The study above is relevant with research in Togo, Paris that ages below 35 years influences on LTFU with (RR 1.6; 95\% CI: 1.3 - 2.0; p <0.001), [13] while in Ethiopia, it is stated that productive age of teens affect twice and adults 1.44 times affect LTFU. The adolescence may be very uncertain in taking ARV, they do not have caregivers (different with younger age), and they show immaturity in analytical thinking, because there are special challenges due to the puberty. Furthermore, they are active in other activities, so it will affect LTFU as well. The previous research also showed that adherence in adolescents is lower than the adults [14], [15]. Many adolescents and adults are LTFU. During adolescence, parental involvement is often denied when young men and women try to establish their identity separately from their parents and caregivers. When adolescents seek independence, social acceptance is also a key, with a strong desire to "adjust". For some of the HIVpositive adolescents in this study, taking ARV drugs was considered dangerous to the confidentiality, and they need to choose between missing a dose of ART or carrying ARV drugs with them, also it gave a risk revealing their diagnosis [16]. Based on the results of research from D, Fillimau et al, 2019 patients with age less than 35 years old have a tendency to be more non-adherent to ARVs, so the risk of increasing LTFU is growing. Teenagers are important parts of the high-risk group of LTFU, so we need a way to deal with challenges related to treatment that can contribute to better levels of non-compliance [17], [18].

But this is different from research in Tanzania, sub-Saharan Africa mentions the tendency of more than 50 years old patients to be hospitalized with CD4 counts $<100$ having an increased risk for LTFU (RR: 1,11, 95\% CI 1,03 - 1,19, p $<0,0001$ [19], whereas according to by Nachega et al from South Africa. It revealed that adolescents had worse outcomes compared to their adult counterparts. The differentiations may be in socio-cultural characteristics, care protocols, and variations of social support in age groups in various countries.[14], [15] Other studies have shown that older patients are less likely to be lost to followup compared to younger patients (for each of increasing age, it is likely to decrease) [20].

\subsection{Gender and Incidence of LTFU}

The results of this study showed that gender was declared not statistically significant, with $p=1.00$, so it did not show a significant effect on LTFU in the Semarang area. This is consistent with a study in Ethiopia that there are no gender differences in LTFU [14],but different from other studies that show that men are potentially lost to follow up in ARV (LTFU) due to the variations in mobility and the high risk of drug abuse in men, which can interfere adherence [21], especially if you have smoking habit, it will affect the HIV/AIDS survival patients (PLWH) $(\mathrm{HR}=2.82 ; 95 \% \mathrm{CI}=$ 1.05 to 7.56 [22]. This study is also in accordance with studies in Cuba that male sex addicted to drugs can experience higher toxicity due to interactions with ARV drugs that lead to the termination of ARVs. They tend to be LTFU and they are close to the death. This cannot be separated from social, demographic, cultural influences, etc. [15], [23], [24]. A research in Paris shows that female sex affects the first 6 months of LTFU with the risk of OR= 1.8; 95\% CI: 1.3-2.5 [13]. . Based on the study of charurat $\mathrm{M}$, et al in Tanzania, sub-Saharan Africa, there is a tendency for patients over 50 years old and hospitalized with CD4 counts $<100$ having a risk of increasing LTFU (RR: 1.11, $95 \%$ CI $1.03-1.19, \mathrm{p}<0.0001[18]$.

\subsection{Education and Incidence of LTFU}

The results showed that Education $p=0.127$, so it was stated that it did not affect statistically on LTFU in the Semarang area. This study is consistent with the statement that the level of education has no effect on ARV noncompliance, whereas ARV non-compliance has the opportunity to LTFU [17]. This is different from the study in Cuba, which states that education affects adherence and 
reduces LTFU. With the ARV adherence, ARV is increasing based on people's age and higher level of education [23]. While according to Januraga, in key populations, it is shown that higher education (high school or university) is significantly more likely to achieve viral suppression compared to elementary school or lower level of education ( $\mathrm{p} \leq 0.09$ by multivariate analysis) [20]. While another study in Kenya states that lower education levels risk LTFU with (AOR 3.80, 95\% CI 1.14-12.7; P 0.03) [25]. In Nigerian research, lower levels of education have an effect on non-compliance [26], if basic education risks increasing LTFU with $\mathrm{p}=0,02$ while post-secondary education was stated to reduce LTFU $\mathrm{p}=0.03$ [18].

\subsection{Employment and Incidence of LTFU}

Based on this research, the employment status variable was statistically significant $(\mathrm{OR}=3.029 ; 95 \% \mathrm{CI}=1.020$ to $8.992 ; \mathrm{p}=0.042$ ). Analysis of Chi-square showed that there was an influence of employment status on LTFU. The employment status of people living with HIV/AIDS (PLWH) who does not have a job is at risk for LTFU. This study is relevant to the statement that unemployment status has a risk of LTFU in Ethiopia with (AHR, 2.22, 95\% CI 1.2-4.11). Unemployed patients have an increased risk of becoming LTFU when compared to government employees/NGOs. This may be due to lack of money for transportation, food, etc. So it prevents the follow-up of ART regularly [27]. Unemployment status can also represent further disease markers [28]. Another reason is that people who are employed are $31 \%$ less likely to get out of care than those who are unemployed. People living with HIV/AIDS (PLWH) who are unemployed are less likely to be in a stable relationship. People living with HIV/AIDS (PLWH) tend to move around the place, paying incidental costs associated with obtaining health care [29]. The research shows employment status influences LTFU. Due to the continual work every day, the patient does not have time to take ARVs or to go to a health facility [30]. The difference with the research of Karcher et al. is the employment status has no effect on LTFU in Kenya and it is stated that it is not significant after conducting the multivariate test [25], [31]. Other studies state the type of work does not affect ARV compliance $\mathrm{p}=0.552$ [17].

\subsection{Marital and incidence of LTFU}

The results showed that marital status with $p=0.826$ so that it was statistically not significant. This study is relevant to researches conducted in Togo, Paris with $p=0.07$ and Ethiopia that marital status is not significant to LTFU as well as in Uganda [13], [27], [31], But, it is different from a research in India that states that marital status with the single category influences LTFU [21], whereas according to Filimao et al. people living with HIV (PLWH) patients were widowed and with older age had better ARV compliance rates (aHR: $0.843,95 \%$ CI: $0.738-0.964, p=$ 0.012 ). Those who have no partners tend to have no support and more likely to be negatively affected by the stigma related to HIV and this proves to be a barrier to the adherence and retention in care and treatment [17]

\section{CONCLUSION}

Predisposing factors of age and employment status increase the risk of occurrence of Loss to Follow Up in patients with HIV and AIDS who carry out ARV therapy. Therefore, counseling from the Health Department and family's support for sufferers to do ARV therapy are very important.

\section{REFERENCES}

[1] UNAIDS, "Indicators for monitoring the 2016 Political Declaration on Ending AIDS," 2018.

[2] Peter MacPherson Mosa Moshabela Neil Martinson Paul Pronyk, "lfu RURAL SIUTH AFRICA." Volume 103, Issue 6, 1 June 2009, Pages 588-593, 2008.

[3] M. Kes et al., “Kemenkes 2018," Data dan Inf. profil Kesehat. Indones. tahun 2019, 2018.

[4] F. U. PKMK, Catatan atas Kebijakan dan Program HIV \& AIDS di Indonesia, 1st ed. Yogyakarta, 2016.

[5] B. Rama, S. Syed-abdul, A. Kumar, and U. Iqbal, "mHealth : An updated systematic review with a focus on HIV/AIDS and tuberculosis long term," Comput. Methods Programs Biomed., vol. 122, no. 2, pp. 257265, 2015.

[6] H. Tweya et al., "Loss to follow-up before and after initiation of antiretroviral therapy in HIV facilities in Lilongwe, Malawi,” vol. 907, pp. 1-12, 2018.

[7] C. K. McMullen et al., "Patient-centered priorities for improving medication management and adherence," Patient Educ. Couns., vol. 98, no. 1, pp. 102-110, 2015.

[8] S. K. Yulidar, evy yunihastuti, Samsuridjal Djauzil, Astrid Citra Padmita, "Factors Associated with Retention in Care One Year after Delivery in Patients Undergoing Prevention of Mother to Child Transmission (PMTCT) at RSCM," J. penyakit dalam Indones., vol. 4, no. 2, pp. 68-72, 2017.

[9] K. Torpey et al., "Adherence and retention on antiretroviral therapy in a public-private partnership program in Nigeria," J. Int. AIDS Soc., vol. 15, no. 6(Suppl 4), pp. 1-9, 2012.

[10] L. S. Wilkinson, J. Skordis-Worrall, O. Ajose, and N. Ford, "Self-transfer and mortality amongst adults lost to follow-up in ART programmes in low- and middle-income countries: Systematic review and meta- 
loss to follow up after antiretroviral therapy initiation: data from an HIV cohort study in India," vol. 1, pp. 18, 2013.

[22] T. Susilowati, T. Nur Kristina, and M. Au Sofro, "Effect of Smoking on Survival among HIV/AIDS Patients in Kedu, Central Java," icph uns, pp. 92-92, 2018.

[12] M. R. Lamb, W. M. El-sadr, E. Geng, and D. Nash, "Association of Adherence Support and Outreach Services with Total Attrition, Loss to Follow-Up , and Death among ART Patients in Sub-Saharan Africa," vol. 7, no. 6, 2012.

[13] B. Saka et al., "Loss of HIV-infected patients on potent antiretroviral therapy programs in Togo: Risk factors and the fate of these patients," Pan Afr. Med. J., vol. 15, pp. 1-7, 2013.

[14] T. M. Berheto, D. B. Haile, and S. Mohammed, "Predictors of Loss to follow-up in Patients Living with HIV/AIDS after Initiation of Antiretroviral Therapy," vol. 6, no. 9, pp. 453-459, 2014.

[15] T. Moshago, D. B. Haile, and F. Enkusilasie, "Survival Analysis of HIV Infected People on Antiretroviral Therapy at Mizan-Aman General Hospital, Southwest Ethiopia," vol. 3, no. 5, pp. 1462 1468, 2014.

[16] J. T. Galea et al., "Barriers and facilitators to antiretroviral therapy adherence among Peruvian adolescents living with HIV: A qualitative study," PLoS One, vol. 13, no. 2, pp. 1-19, 2018.

[17] D. B. C. Filimão, T. D. Moon, J. F. Senise, R. S. Diaz, M. Sidat, and A. Castelo, "Individual factors associated with time to non-adherence to ART pick-up within HIV care and treatment services in three health facilities of Zambézia Province, Mozambique," PLoS One, vol. 14, no. 3, pp. 1-15, 2019.

[18] M. Charurat et al., "Patient Retention and Adherence to Antiretrovirals in a Large Antiretroviral Therapy Program in Nigeria : A Longitudinal Analysis for Risk Factors," vol. 5, no. 5, 2010.

[19] L. C. Machumi et al., "Who are they ? Identifying risk factors of loss to follow up among HIV + patients on care and treatment in Dar es Salaam," vol. 14, no. Suppl 2, p. 2334, 2014.

[20] P. P. Januraga et al., "Articles The cascade of HIV care among key populations in Indonesia: a prospective cohort study," Lancet HIV, vol. 3018, no. 18, pp. 1-9, 2018.

[21] G. Alvarez-uria, P. K. Naik, R. Pakam, and M. Midde, "Factors associated with attrition, mortality, and
[23] C. Aragonés, L. Sánchez, J. R. Campos, and J. Pérez, "Antiretroviral therapy adherence in persons with HIV/AIDS in Cuba.," MEDICC Rev., vol. 13, no. 2, pp. 17-23, 2011.

[24] L. Li, S. J. Lee, Y. Wen, C. Lin, D. Wan, and C. Jiraphongsa, "Antiretroviral therapy adherence among patients living with HIV/AIDS in Thailand," Nurs. Heal. Sci., vol. 12, no. 2, pp. 212-220, 2010.

[25] H. Karcher, A. Omondi, J. Odera, A. Kunz, and G. Harms, "Risk factors for treatment denial and loss to follow-up in an antiretroviral treatment cohort in Kenya," Trop. Med. Int. Heal., vol. 12, no. 5, pp. 687694, 2007.

[26] S. M. Bulsara, M. L. Wainberg, and T. R. O. Newton-John, "Predictors of Adult Retention in HIV Care: A Systematic Review," AIDS Behav., vol. 22, no. 3, pp. 752-764, 2018.

[27] N. Mekonnen, M. Abdulkadir, E. Shumetie, A. G. Baraki, and M. K. Yenit, "Incidence and predictors of loss to follow-up among HIV infected adults after initiation of first line anti-retroviral therapy at University of Gondar comprehensive specialized Hospital Northwest Ethiopia, 2018: Retrospective follow up study," BMC Res. Notes, vol. 12, no. 1, pp. 1-7, 2019.

[28] I. V Bassett et al., "NIH Public Access," vol. 51, no. 2, pp. 135-139, 2009.

[29] M. H. Aliyu, M. Blevins, K. M. Megazzini, D. D. Parrish, and C. M. Audet, "Pregnant women with HIV in rural Nigeria have higher rates of antiretroviral treatment initiation, but similar loss to follow-up as non-pregnant women and men," pp. 405-411, 2015.

[30] I. Ahmed, S. T. Gugsa, S. Lemma, and M. Demissie, "Predictors of loss to follow-up before HIV treatment initiation in Northwest Ethiopia : a case control study," vol. 333434, no. June 2011, 2013.

[31] M. Kweyamba, E. Buregyeya, J. Kusiima, V. Kweyamba, and A. D. Mukose, "Loss to Follow-Up among HIV Positive Pregnant and Lactating Mothers on Lifelong Antiretroviral Therapy for PMTCT in Rural Uganda," vol. 2018, 2018. 